\title{
Stochastic Population Model for Electrical Stimulation of the Auditory Nerve
}

\author{
Nikita S. Imennov and Jay T. Rubinstein, Senior Member, IEEE
}

\begin{abstract}
We have developed a biophysical model of a population of electrically-stimulated auditory nerve fibers. It can be used to interpret results from physiological and behavioral experiments with cochlear implants, and to propose novel stimulation strategies. Our model consists of myelinated internodes described by a passive resistor-capacitor network, membrane capacitance and leakage current at the nodes of Ranvier, as well as stochastic representations of nodal voltagedependent channels $\left(\mathrm{Na}, \mathrm{K}_{\mathrm{f}}\right.$, and $\left.\mathrm{K}_{\mathrm{s}}\right)$.

To approximate physiological properties measured in the auditory nerve (AN) of an acutely deafened cat, electrical parameters of the model fiber were chosen based on literature-reported values. Using our model, we have replicated the following properties within $10 \%$ of the reported ([1]-[4]) feline single-fiber measurements: relative spread $(5.8 \%)$, spike latency $(630 \mu \mathrm{s})$, jitter $(93 \mu s)$, chronaxie $(238 \mu s)$, relative refractory period $(4.6 \mathrm{~ms})$, and conduction velocity $(14 \mathrm{~m} / \mathrm{s})$. Moreover, we have successfully matched response characteristics of a population of fibers with the same number of diameter-distributed model fibers, enabling us to simulate responses of the entire auditory nerve. To demonstrate the performance of our model, we compare responses of a population of ANs stimulated with two speech encoding strategies, Continuous Interleaved Sampling (CIS) and Compressed Analog (CA).
\end{abstract}

Index Terms - Cochlear implants, electrical stimulation, neural prosthesis, auditory nerve fibers, stochastic ion channels, relative spread, temporal jitter, ion channel gating, sensory coding.

\section{INTRODUCTION}

A LTHOUGH speech perception among cochlear implant users has been steadily increasing over the past 25 years, many users do not achieve sentence recognition scores over $80 \%$, and the presence of background noise further degrades their performance $(c f .[5],[6])$. Laszig et al. have shown that binaural cochlear implants can improve sound localization and speech perception in noise [7]. However, implantees do not perform as well as normal listeners on binaural tasks, possibly because the benefits of binaural hearing depend partly on users' ability to encode interaural timing differences [8]. Improvements

* N. S. Imennov is with the Dept. of Bioengineering, Univ. of Washington, Seattle, WA 98195. Email: 〈imennov at u.washington.edu〉

J. T. Rubinstein is with the Depts. of Bioengineering and Otolaryngology - Head \& Neck Surgery, as well as the Virginia Merrill Bloedel Hearing Research Center, Univ. of Washington, Seattle, WA 98195.

Copyright (C) 2008 IEEE. Personal use of this material is permitted. However, permission to use this material for any other purposes must be obtained from the IEEE by sending an email to pubspermissions@ieee.org. in encoding temporal information can overcome some of these limitations and may also aid implantees' perception of tonal languages via improved pitch coding [9], and music via rhythm, melody, and timbre [10], [11].

To enhance our understanding of how auditory nerves (AN) encode timing, frequency, and intensity information, a number of computational models of electrically stimulated mammalian nerve fibers have been developed [12][17]. Deterministic models, such as the one proposed by Frijns et al. can predict a number of important properties, such as threshold, firing rate, and conduction velocity of an individual fiber, or a population of fibers [18]. However, deterministic models fail to accurately represent the probabilistic firing of nerves, a property which has been argued to be key in describing how the AN encodes information [19]-[21].

To address this limitation, some phenomenological models (e.g., [1], [19]) include a Gaussian noise term in calculation of the membrane current. However, axonal excitability and membrane noise change concomitantly with the state of ion channels [22], [23], which becomes particularly relevant at higher rates of stimulation [24], [25]. Therefore, to accurately describe temporal (e.g., latency) and probabilistic (e.g., relative spread, jitter) response properties of fibers, a model of electrically-stimulated auditory nerve needs to represent the stochastic nature of ion channels.

To construct a robust population model of an auditory nerve, we first matched the behavior of our stochastic model to that of a single mammalian fiber. Since properties of cat auditory nerve have been extensively studied [1], [3], [26]-[28], whenever possible, we optimised our model's response to match the behavior of feline auditory nerve fibers.

Having met reported values for chronaxie, latency, jitter, and relative spread, we constructed a diameter-distributed population of nerve fibers and successfully replicated an in vivo response of a neural population. Finally, we used our newly-validated population model to simulate and visualise the response of the auditory nerve to two sound encoding strategies - Continuous Interleaved Sampling and Compressed Analog (CIS, [29] and CA, [30], respectively).

\section{Methods}

\section{A. Computational Model}

The spatially distributed, stochastic model used in this study is based on the morphology of a typical feline Type 
TABLE I

MORPHOLOGICAL PARAMETERS OF A SINGLE MODEL FIBER

\begin{tabular}{|c|c|c|}
\hline Parameter & Value & Ref. $^{\mathrm{a}}$ \\
\hline Axon diameter & $1.5 \mu \mathrm{m}$ & {$[31]$} \\
\hline Axon/fiber ratio & 0.6 & {$[32],[33]$} \\
\hline Fiber Diameter & $2.5 \mu \mathrm{m}$ & \\
\hline \multicolumn{3}{|l|}{ Nodes of Ranvier: } \\
\hline Nodal length & $1 \mu \mathrm{m}$ & [34] \\
\hline Constriction factor & 0.5 & {$[31]$} \\
\hline \multicolumn{3}{|l|}{ Internodes: } \\
\hline Total num. & 36 & \\
\hline Segments per $\sim$ & 9 & \\
\hline Length/Diam. ratio & $92: 1$ & {$[31],[32]$} \\
\hline Length & $230 \mu \mathrm{m}$ & \\
\hline Timestep & $1 \mu \mathrm{s}$ & \\
\hline
\end{tabular}

I spiral ganglion peripheral process, described in Table I. Implementation details of the model have remained the same as reported in Mino et al., [35], save for the modification of model parameters to more accurately represent the behavior of a mammalian auditory nerve.

Nodes of Ranvier in a fiber consist of voltage-dependent ion channels and passive membrane components (resistance, capacitance). The number of channels at each node is calculated based on each channel's density, multiplied by the geometric surface area of the node,

$$
\mathrm{SA}_{\text {node }}=0.5 \pi \times \mathrm{d}_{\text {axon }} \times \mathrm{l}_{\text {node }} \quad[\mu \mathrm{m}],
$$

where 0.5 is the constriction factor [31], $\mathrm{d}_{\mathrm{axon}}$ is the axon diameter, and $l_{\text {node }}$ is the nodal length. A Markov process was used to simulate the stochastic nature of the sodium and potassium channels, while gating parameters governing the opening and closing kinetics were chosen based on values from the biophysical literature.

Unlike the nodes of Ranvier, internodes were modeled using only passive membrane elements - resistance and capacitance. Each internode is represented by nine passive segments (see Fig. 1, "Internodal Segment" label), with total length of the internode calculated from the diameter of individual fibers. Specifically, we used a constant ratio of 92:1, measured in feline peripheral AN fibers (see "Length/Diam. ratio" entry in Table I). Since largerdiameter fibers would be longer than smaller-diameter fibers as a result of using this constant ratio, we normalised the number of internodes in a fiber such that the extent to which a fiber is simulated would be the same, regardless of its diameter (see Fig. 1). Thus, we avoid unnecessary computation by calculating response only in nodes located before the simulation boundary.

Parameter optimisation was performed manually, in an iterative manner. First, we optimised density, conductivity, and gating of the ion channels to roughly approximate relative spread of the fiber and its conduction velocity. Next, we iterated over a range of literature-reported electrical parameters to approximate nodal and internodal time constants by measuring chronaxie of the model fiber.

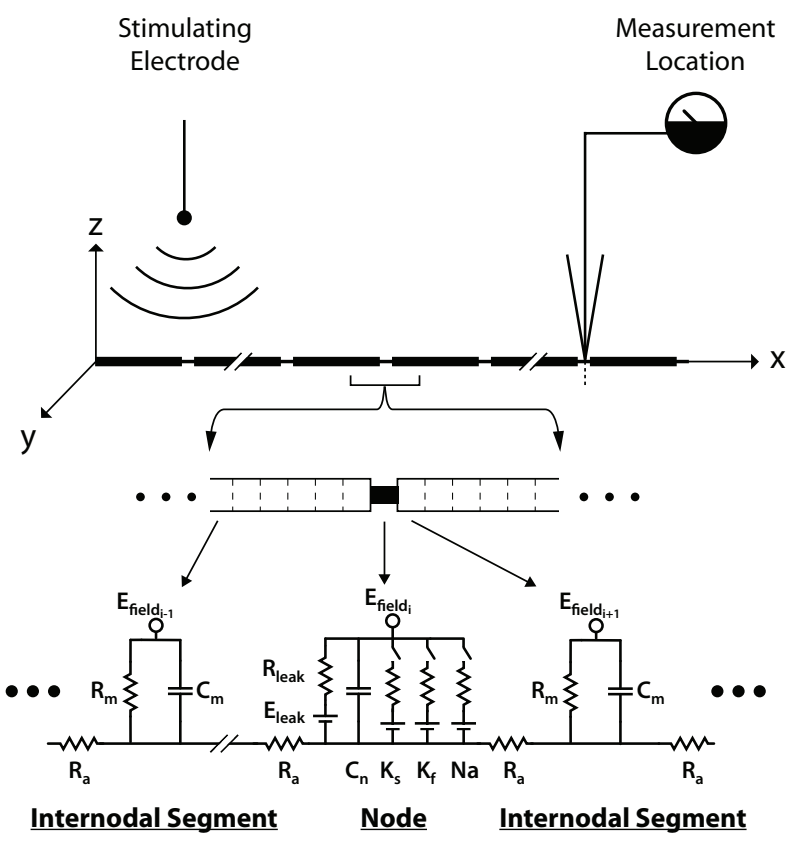

Fig. 1. Model of Type I spiral ganglion peripheral process. Note stochastic channels at nodes of Ranvier; internodes composed of identical passive-element segments. Not to scale.

After chronaxie was judged to be close to the target value, we returned to optimising channel parameters, this time paying attention to how all of the chosen measures ( $c f$. Table V) were affected. The above steps were repeated until fiber properties were within $10 \%$ of the published values. Details of specific optimisation steps are described next.

1) Optimising Parameters of Ion Channels: In fitting our model to replicate the behavior of single fibers, we varied two parameters for every type of ion channel its conductivity and its density. For sodium channels, intended to model $\mathrm{Na}_{\mathrm{v}} 1.6$ currents ( $c f$. [36]), we varied parameters within the ranges commonly reported in the literature. Due to the number of studies and a variety of experimental conditions, however, values reported for single-channel conductivity of $\mathrm{Na}\left(\gamma_{\mathrm{Na}}\right)$ and channel density varied tremendously. Initially, we allowed the density of $\mathrm{Na}$ channels to vary from 700 to $2000 \mathrm{chan} / \mathrm{\mu m}^{2}$ [37], but have found that the model was better behaved toward the lower end of the range, at 618 channels per $\mu^{2}$.

Initial value for single-channel conductivity of $\mathrm{Na}$ was based on $\gamma_{\mathrm{Na}}=6.4 \pm 1 \mathrm{pS}[38]$. However, since the original experiment was performed at $4^{\circ} \mathrm{C}$, the measurement had to be temperature-adjusted to $37^{\circ} \mathrm{C}$. Temperature dependence for $\mathrm{Na}$ conductivity, as specified by a $\mathrm{Q}_{10}$ value, varies from 1.3 to 1.6 [37, pg. 396], which results in a range of initial $\gamma_{\mathrm{Na}}$ values of $15.2 \pm 2.4$ to $30.2 \pm 4.7 \mathrm{pS}$. Given the large range of $\gamma_{\mathrm{Na}}$ values, we decided to keep conductivity in our model fixed at $20 \mathrm{pS}$, as it was close to the $18 \mathrm{pS}$ reported by Sigworth and Neher in cultured rat muscle cells (at $18-22^{\circ} \mathrm{C},[39]$ ), and close to Neumcke's measurements of $\gamma_{\mathrm{Na}}=17.3 \pm 2.1 \mathrm{pS}(\mu \pm \mathrm{SEM} ; 10$ measurements on 8 fibers) in rat sciatic nerve at $20^{\circ} \mathrm{C}$ [40]. 
Potassium current was modeled as two separate components - a fast one, $\mathrm{K}_{\mathrm{f}}$, intended to represent intermediate and fast $\mathrm{K}^{+}$channels' current ( $\mathrm{I}-$ and $\mathrm{F}$ - channels in [41]), and a slow component, $\mathrm{K}_{\mathrm{s}}$. Rapidly activating and transient, $\mathrm{K}_{\mathrm{f}}$ current was included in our model to shorten the relative refractory period. The delayed rectifier current of $\mathrm{K}_{\mathrm{s}}$, on the other hand, was included for its role in accommodation to subthreshold depolarisation currents and spike-frequency adaptation processes [42].

The starting range for conductivity of individual slow potassium channels was based on the values measured in human axons [43]. However, since the original study was performed at $22-27^{\circ} \mathrm{C}$, the reported range of $7-10 \mathrm{pS}$ was temperature-corrected to $8-13 \mathrm{pS}$ at $37^{\circ} \mathrm{C}\left(\mathrm{Q}_{10}=1.2\right.$, [44, pg. 88]). The $\gamma_{\mathrm{K}_{\mathrm{s}}}$ value derived for our model lies in the middle of this starting range, at $10 \mathrm{pS} /$ channel. Conductivity of slow potassium channels used in our model also fall in line with temperature-adjusted measurements reported earlier by Scholz et al.: $9.8-10.5 \mathrm{pS}$ (orig: $\gamma_{\mathrm{K}_{\mathrm{s}}}$ $=8 \mathrm{pS}$ at $24 \pm 2^{\circ} \mathrm{C}$, [45]). We allowed the density of $\mathrm{K}_{\mathrm{s}}$ channels to vary from a floor value of $30 \mathrm{chan} / \mathrm{\mu m}^{2}$ to $110 \mathrm{chan} / \mathrm{\mu m}^{2}$ reported by [37, pg. 330][41], and as a result of optimisation, found the values converge to $41.2 \mathrm{e} 6$ chan $/ \mathrm{mm}^{2}$.

Given the lack of gating kinetics data for I- and F- fast potassium channels, we amalgamated these currents into one fast-acting potassium channel $\mathrm{K}_{\mathrm{f}}$, as has been done in [46]. However, since we did not explicitly model paranodal sections of the axon (i.e., MYSA and FLUT ${ }^{*}$ ), but instead placed $\mathrm{K}_{\mathrm{f}}$ channels at the node of Ranvier, we used 5$10 \mathrm{pS}$ as the starting range for $\gamma_{\mathrm{K}_{\mathrm{f}}}$ (" $\mathrm{I}_{\mathrm{A}}$ " in [47, pg. 181]), and fixed the channel density to half of $\mathrm{K}_{\mathrm{s}}$ 's.

2) Optimising Gating Parameters: Gating parameters governing channel kinetics were based on the values reported by Schwarz et al. and McIntyre et al., [46], [48]. Our only modifications of the reported values were to adjust Schwarz's rate constants from $20^{\circ} \mathrm{C}$ to $37^{\circ} \mathrm{C}$, and to alter half-maximal voltages for $\mathrm{Na}$ and $\mathrm{K}_{\mathrm{f}}$ to reflect different ion concentrations reported in which $\mathrm{I}_{\mathrm{K}_{\mathrm{f}}}$ and $\mathrm{I}_{\mathrm{Na}}$ were measured. Specifically, activation for $\mathrm{Na}$ was changed from $\alpha_{m}=-20.4 \mathrm{mV}$ to $-27.4 \mathrm{mV}$, and half-maximum values for fast potassium were changed to $\alpha_{n}=-93.2 \mathrm{mV}$; $\beta_{n}=-76.0 \mathrm{mV}$ (from -83.2 and $-66.0 \mathrm{mV}$, respectively). We have found that raising $\alpha_{m}$ to $-27.4 \mathrm{mV}$ increased the relative spread of a fiber from $\sim 1.5 \%$ at $\alpha_{m}=-20.4 \mathrm{mV}$ to $\sim 6 \%$ at $-27.4 \mathrm{mV}$.

3) Electrical Parameters of the Fiber: Initial values for nodal resistance and capacitance in our model were set at $831 \Omega \cdot \mathrm{mm}^{2}$ and $2 \mathrm{e}-5 \mathrm{nF} / \mathrm{mm}^{2}$, respectively [49], [50]. After the fitting process, we found that the final value for nodal capacitance, $2.05 \mathrm{e}-5 \mathrm{nF} / \mathrm{mm}^{2}$ was not significantly different from its initial value. The final value for nodal resistance, however, was 10 times above its initial value, at $8310 \Omega \cdot \mathrm{mm}^{2}$. Compared to previously-reported parameters, this is approximately midway between the

*MYSA: Myelin sheath attachment axon segment; FLUT: Fluted paranodal axon segment, see [44, pg. 22] or [46, pg. 996] for more.
TABLE II

GATING KINETICS

\begin{tabular}{|c|c|c|c|c|c|}
\hline \multicolumn{2}{|c|}{$\begin{array}{c}\text { Rate } \\
\text { Constants }^{a}\end{array}$} & $\begin{array}{c}\mathbf{A}^{\mathbf{b}} \\
\left(\mathbf{m s}^{-1}\right)\end{array}$ & $\begin{array}{c}\text { B } \\
(\mathbf{m V})\end{array}$ & $\begin{array}{c}\mathrm{C} \\
(\mathrm{mV})\end{array}$ & Ref. \\
\hline \multirow{4}{*}{$\mathrm{Na}$} & $\alpha_{m}$ & 6.57 & 27.4 & 10.3 & \multirow{4}{*}[46]{} \\
\hline & $\beta_{m}$ & 0.304 & -25.7 & 9.6 & \\
\hline & $\alpha_{h}$ & 0.34 & -114.0 & 11.0 & \\
\hline & $\beta_{h}$ & 12.6 & -31.8 & 13.4 & \\
\hline \multirow{2}{*}{$\mathbf{K}_{\mathbf{f}}$} & $\alpha_{n}$ & 0.0462 & -93.2 & 1.10 & \multirow{2}{*}{ [46] } \\
\hline & $\beta_{n}$ & 0.0824 & -76.0 & 10.5 & \\
\hline \multirow{2}{*}{$\mathbf{K}_{\mathrm{s}}$} & $\alpha_{s}$ & 0.3 & -12.5 & 23.6 & \multirow{2}{*}{$\begin{array}{c}{[46],[48]} \\
{[48]}\end{array}$} \\
\hline & $\beta_{s}$ & 0.003631 & -80.1 & 21.8 & \\
\hline
\end{tabular}

${ }^{\text {a }}$ All of the above values are valid at $37^{\circ} \mathrm{C}$, which in some cases necessitated adjustment of $\mathrm{A}$ by multiplying it with $\mathrm{k}=\mathrm{Q}_{10}^{\left(37-\mathrm{T}_{\mathrm{o}}\right) / 10}$, where $\mathrm{T}_{\mathrm{o}}$ is the temperature at which the original experiments were performed, and $\mathrm{Q}_{10}$ is an appropriate temperature factor (see text).

Values in bold are modified from cited references (see text).

${ }^{\mathrm{b}}$ Constants A, B, C were derived from the following equations:

$$
\begin{aligned}
\alpha_{m}, \alpha_{n}, \alpha_{s} & =\mathrm{A}(\mathrm{E}-\mathrm{B}) /\{1-\exp [(\mathrm{B}-\mathrm{E}) / \mathrm{C}]\} \\
\alpha_{h}, \beta_{m}, \beta_{n}, \beta_{s} & =\mathrm{A}(\mathrm{B}-\mathrm{E}) /\{1-\exp [(\mathrm{E}-\mathrm{B}) / \mathrm{C}]\}, \\
\beta_{h} & =\mathrm{A} /\{1+\exp [(\mathrm{B}-\mathrm{E}) / \mathrm{C}]\}
\end{aligned}
$$

where the variable $\mathrm{E}$ represents membrane potential in $\mathrm{mV}$, and the rest of the variables are based on the cited references.

\begin{tabular}{|c|c|c|}
\hline & Value & Ref. \\
\hline $\begin{array}{l}\text { Node of Ranvier: } \\
\text { Resistance, } r_{m} \\
\text { Capacitance, } c_{m}\end{array}$ & $\begin{array}{c}831 \Omega \cdot \mathrm{mm}^{2} \\
2.05 \mathrm{e}-5 \mathrm{nF} / \mathrm{mm}^{2}\end{array}$ & $\begin{array}{c}{[48],[49]} \\
{[50]}\end{array}$ \\
\hline $\begin{array}{l}\text { Na density } \\
\gamma_{\mathrm{Na}} \\
\mathrm{K}_{\mathrm{S}} \text { density } \\
\gamma_{\mathrm{K}_{\mathrm{s}}} \\
\mathrm{K}_{\mathrm{f}} \text { density } \\
\gamma_{\mathrm{K}_{\mathrm{f}}}\end{array}$ & $\begin{array}{c}700-2000 \mathrm{chan} / \mathrm{\mu m}^{2} \\
15-30 \mathrm{pS} / \mathrm{chan}^{2} \\
30-110 \mathrm{chan} / \mathrm{\mu m}^{2} \\
8-13 \mathrm{pS} / \mathrm{chan} \\
5-10 \mathrm{pS} / \text { chan }\end{array}$ & $\begin{array}{c}{[37],[44]} \\
{[37],[38]} \\
{[37],[41]} \\
{[43]}\end{array}$ \\
\hline $\begin{array}{l}\text { Internode: } \\
\text { Resistance, } \mathrm{r}_{\mathrm{mmy}} \\
\text { Capacitance, } \mathrm{c}_{\mathrm{mmy}}\end{array}$ & $\begin{array}{c}209 \mathrm{e} 6 \Omega \cdot \mathrm{mm} \\
1.63 \mathrm{e}-9 \mathrm{nF} / \mathrm{mm}\end{array}$ & $\begin{array}{l}{[50]} \\
{[50]}\end{array}$ \\
\hline Axoplasmic resist., $\mathrm{R}_{i}$ & $700-1063 \Omega \cdot \mathrm{mm}$ & {$[40],[51]$} \\
\hline
\end{tabular}

TABLE III

INITIAL ELECTROPHYSIOLOGICAL PARAMETERS

measurements in [48], $1625 \Omega \cdot \mathrm{mm}^{2}$, and the model value in [46], $14286 \Omega \cdot \mathrm{mm}^{2}$. The aggregate effect of the changes to the nodal resistance and capacitance is best captured by the changes to the time constant of the nodal membrane, $\tau_{\mathrm{m}}=\mathrm{r}_{\mathrm{m}} \mathrm{c}_{\mathrm{m}}$. As a result of parameter optimisation, the final value of $\tau_{\mathrm{m}}$ was 10.25 times its initial value.

In fitting our model to match the behavior of a mammalian fiber, we expected to modify internodal parameters the most, since the starting values were based on the data obtained from amphibian nerve fibers. We centered our estimates for internodal resistance and capacitance at $209 \mathrm{M} \Omega \cdot \mathrm{mm}$ and $1.63 \mathrm{e}-9 \mathrm{nF} / \mathrm{mm}$, respectively, and allowed the parameters to vary within 1.5 orders of magnitude [50]. In order to replicate experimentally observed behavior of feline nerve fibers, internodal resistance of our model had to be set at six times the initial value, at $1254 \mathrm{M} \Omega \cdot \mathrm{mm}$, while the capacitance had to be set to $1 / 11$ th of its original value, to $1.45 \mathrm{e}-10 \mathrm{nF} / \mathrm{mm}$. As a result of 
TABLE IV

FinAl ELECTROPHySIOLOGiCAL PARAMETERS OF THE TUNED MODEL

\begin{tabular}{|c|c|c|}
\hline & Value & Ref. \\
\hline $\begin{array}{l}\text { Node of Ranvier: } \\
\text { Resistance, } \mathrm{r}_{\mathrm{m}} \\
\text { Capacitance, } \mathrm{c}_{\mathrm{m}}\end{array}$ & $\begin{array}{c}8310 \Omega \cdot \mathrm{mm}^{2} \\
2.05 \mathrm{e}-5 \mathrm{nF} / \mathrm{mm}^{2}\end{array}$ & $\begin{array}{c}{[48],[49]} \\
{[50]}\end{array}$ \\
\hline $\begin{array}{l}\text { Na channels: } \\
\text { Eq. potential } \\
\text { Density } \\
\gamma_{\mathrm{Na}}\end{array}$ & $\begin{array}{l}50 \mathrm{mV} \\
618 \mathrm{chan} / \mathrm{\mu m}^{2} \\
20 \mathrm{pS} / \mathrm{chan}^{2}\end{array}$ & [48] \\
\hline $\begin{array}{l}\mathbf{K}_{\mathbf{s}} \text { channels: } \\
\text { Eq. potential } \\
\text { Density } \\
\gamma_{\mathrm{K}_{\mathrm{s}}}\end{array}$ & $\begin{array}{l}-84 \mathrm{mV} \\
41.2 \mathrm{chan} / \mathrm{\mu m}^{2} \\
10 \mathrm{pS} / \mathrm{chan}^{2}\end{array}$ & [48] \\
\hline $\begin{array}{l}\mathbf{K}_{\mathbf{f}} \text { channels: } \\
\text { Eq. potential } \\
\text { Density } \\
\gamma_{\mathrm{K}_{\mathrm{f}}} \\
\end{array}$ & $\begin{array}{l}-84 \mathrm{mV} \\
20.3 \mathrm{chan} / \mathrm{\mu m}^{2} \\
10 \mathrm{pS} / \mathrm{chan}^{2}\end{array}$ & \\
\hline $\begin{array}{l}\text { Internode: } \\
\text { Resistance, } \mathrm{r}_{\mathrm{mmy}} \\
\text { Capacitance, } \mathrm{c}_{\mathrm{mmy}}\end{array}$ & $\begin{array}{c}1254 \mathrm{e} 6 \Omega \cdot \mathrm{mm} \\
1.45 \mathrm{e}-10 \mathrm{nF} / \mathrm{mm}\end{array}$ & \\
\hline $\begin{array}{l}\text { Axoplasmic resist., } \mathrm{R}_{i} \\
\text { External resistance } \\
\text { Resting potential, } \mathrm{E}_{\mathrm{rest}}\end{array}$ & $\begin{array}{c}733 \Omega \cdot \mathrm{mm} \\
25000 \Omega \cdot \mathrm{mm} \\
-84 \mathrm{mV}\end{array}$ & $\begin{array}{c}{[46],[51]} \\
{[48]}\end{array}$ \\
\hline
\end{tabular}

these changes, time constant of the internodal membrane, $\tau_{\mathrm{mmy}}=\mathrm{r}_{\mathrm{mmy}} \mathrm{c}_{\mathrm{mmy}}$, has changed to approximately half of its initial value.

Surprisingly, we observed that axoplasmic resistance has a large effect on the stochastic properties of a fiber. Namely, if the rest of the parameters are fixed and $\mathrm{R}_{i}$ is raised from $733 \Omega \cdot \mathrm{mm}$ to $1063 \Omega \cdot \mathrm{mm}$, jitter is significantly decreased (from 93 to $\sim 5 \mu \mathrm{s}$ ), along with latency (from 630 to $\sim 430 \mathrm{\mu s}$ ). Therefore, to achieve the desired latency and jitter behavior of our model fiber, the final value for $\mathrm{R}_{i}$ was set to $733 \Omega \cdot \mathrm{mm}$, which is at the lower end of our initial range (see Table IV).

\section{B. Stimulation}

Because the diameter of the modeled fiber is more than an order of magnitude smaller than the electrode-to-fiber distance, the presence of the fiber will not distort the electrical field applied by the stimulating electrode [52]. Thus, the extracellular space was modeled as a homogeneous medium with an isotropic resistivity $\left(\rho_{\text {ext }}=25000 \Omega \cdot \mathrm{mm}\right)$ in which a monopolar, spherical electrode $1 \mu \mathrm{m}$ in radius was placed. Transmembrane voltages were calculated by solving a diffusive partial differential equation via the Crank-Nicholson method (see Appendix in [35]) with the sampling step set to $1 \mu \mathrm{s}$ during all of our simulations.

1) Replicating Experimental Measurements: Stimuli used were identical to those in Miller et al.'s experiments [1], [27], [53], such that our results could be directly compared to the reported physiological measurements. In most

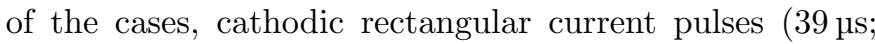
monophasic) were used, except in chronaxie calculations, where the pulse width was varied.

2) CIS and CA Encoding: Parameters for Continuous Interleaved Stimulation (CIS, [29]) and Compressed
Analog (CA, [30]) used in our simulation were chosen to correspond to the settings used in our psychophysical experiments with a single-channel sound processor [54]. Specifically, for CIS encoding, pulse width was set to $75 \mu \mathrm{s}$; stimulation rate was $3250 \mathrm{~Hz}$; and cutoff frequencies of a bandpass filter were set to $350-5500 \mathrm{~Hz}$. Given that the maximum sampling rate used in our particular single-channel sound processor (Platinum Series ${ }^{T M}$ Sound Processor (PSP) by Advanced Bionics Corp.) is $11375 \mathrm{~Hz}$ ( $=91000 \mathrm{~Hz} / 8$ chan $)$, the closest pulse width we could achieve to CIS' $75 \mu$ s was $88 \mu$ s with the analog encoding strategy. Analogously, the closest bandpass filter frequencies were selected when mapping the analog strategy: $250-5500 \mathrm{~Hz}$. It should be noted that in our modeling simulations we used Compressed Analog to encode the input sounds, while the behavioral experiments used a sound processor with Simultaneous Analog Stimulation (SAS), a digital, proprietary implementation of the analog CA, modified by Advanced Bionics Corp. for bipolar stimulation.

To demonstrate the differences in how CIS and CA strategies encode temporal fine structure (TFS) of a sound, we used positive and negative Schroeder phase (SP) harmonic complexes of $50 \mathrm{~Hz}$ as a stimulating waveform [55], [56]. We chose these specific stimuli because we have extensive behavioral response data collected from cochlear implant patients [54]. To assure that an equal amount of charge was applied in each case (CIS or CA encoded $\mathrm{SP}^{+}$ or $\mathrm{SP}^{-}$signal), charge-balanced, biphasic stimuli were normalised by scaling their amplitudes until the integrals of the four waveforms were equal.

\section{Calculation of Fiber Properties}

Whenever membrane potential at the site of the measurement electrode rose above a predefined voltage threshold $\left(\mathrm{V}_{\mathrm{th}}, 50 \mathrm{mV}\right.$ above the resting potential), a spike was said to occur. By counting the number of times a spike was produced at a given intensity, we calculated the firing efficiency (FE), and by varying the intensity of the stimulus and tracking firing efficiency, we obtained the fiber's input-output function.

Single-fiber threshold was defined as the stimulus level at which the firing efficiency is $50 \%$. Latency (the time interval between stimulus onset and generation of a spike), as well as jitter (standard deviation of spike times), were computed at each fiber's threshold levels (i.e., at 50\% FE).

Relative spread (RS), a measure of the fiber's dynamic range due to the probabilistic nature of spike generation, was computed by fitting a Gaussian cumulative distribution function (CDF) to the fiber's input-output curve. To assure an accurate fit to the data, we fit CDF only to non-zero and non-unity $\mathrm{FE}$ values, requiring a minimum of three data points above and three data points below the $50 \% \mathrm{FE}$ level (typically, more than 20 points were used for each RS estimate).

Absolute and relative refractory periods (ARP and $R R P$, respectively) were calculated by varying the maskerprobe interval - first, the fiber was stimulated with a 


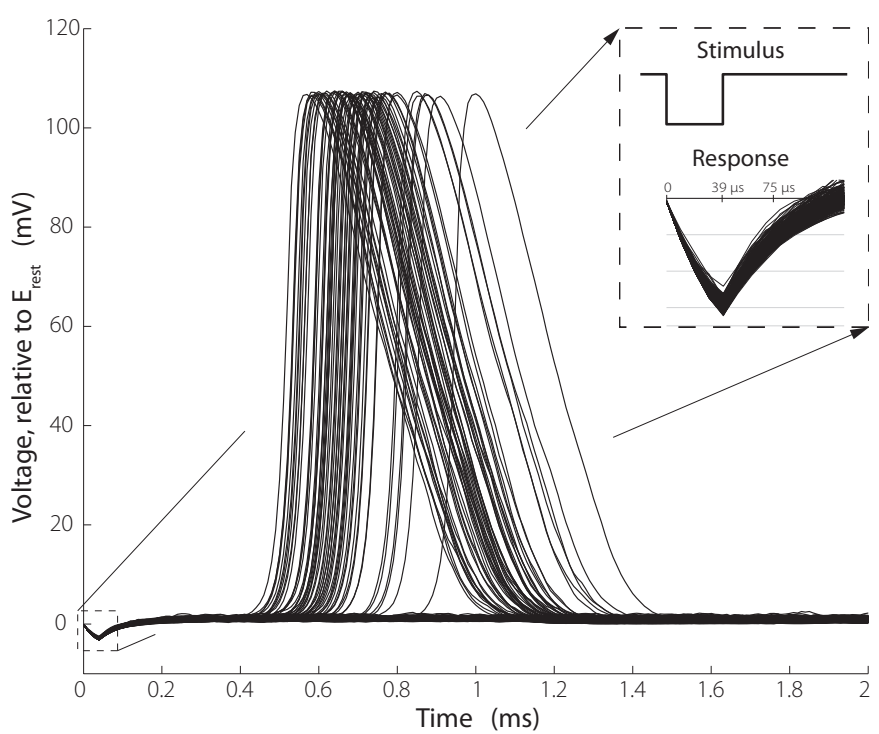

Fig. 2. Voltage at the node of Ranvier in a single fiber (200 trials).

masker current $(\mathrm{FE}=100 \%)$, followed by a second, probe impulse. By tracking the intensity of the probe impulse necessary to elicit a second action potential, we established absolute and relative refractory periods.

Chronaxie, a reflection of the membrane's time constant, is the pulse width necessary to reach a current level that is twice the rheobase (i.e., twice the threshold current of an infinitely-long stimulus). We measured chronaxie with a strength-duration curve by varying the duration of a cathodic, monophasic stimulus from 150 to $3500 \mu \mathrm{s}$.

\section{Results}

\section{A. Single Fiber Response}

A typical response of our optimised, single-fiber model is shown in Fig. 2. We have plotted the voltage at the node of Ranvier closest to the measurement location (see Fig. 1 for schematic). The amplitude of the stimulus was chosen to produce a spike $50 \%$ of the time (i.e., "at threshold," such that $\mathrm{FE}=50 \%$ ). Note how all of the fibers initially display a passive response to the cathodic stimulus (0$39 \mu \mathrm{s})$, but only some of the fibers produce a spike. Also note the delay ("latency") from the time the stimulus is applied at time zero to the time when majority of the fibers fire. On average, that delay is $630 \mu s$, which is close to $647 \pm 142 \mu \mathrm{s}$ (mean $\pm \mathrm{SD}, \mathrm{n}=146)$ experimentally measured by Miller et al., in [27]. In view of significant scatter, likely due to experimental error (as is pointed out in [1]), we, similarly, rounded $647 \mu$ s to $650 \mu s$.

From Fig. 2, one can also see that there is some variability in the times at which the simulated fibers produced a spike. This variability is quantified as jitter, and in our case is equal to $93 \mu \mathrm{s}, 7 \%$ less than Miller's measurement of $\sim 100 \mu \mathrm{s}$ in [1]. The rest of the single-fiber characteristics of our stochastic model are summarised in Table V. Aside from the absolute refractory period, our model approaches all of the cited parameters within $10 \%$ of the mean. Of
TABLE V

COMPARISON OF EXPERIMENTAL AND MODELED SINGLE-FIBER PROPERTIES

\begin{tabular}{l|r|c|r|c} 
Measure & $\begin{array}{c}\text { Model } \\
\text { Fiber }\end{array}$ & $\begin{array}{c}\text { \% } \\
\text { Error }\end{array}$ & $\begin{array}{c}\text { Reported } \\
\text { Values }\end{array}$ & Ref. \\
\hline Relative spread & $5.8 \%$ & $7.9 \%$ & $\sim 6.3 \%$ & {$[1]$} \\
Latency & $630 \mu \mathrm{s}$ & $3.0 \%$ & $\sim 650 \mu \mathrm{s}$ & {$[1]$} \\
Jitter & $93 \mu \mathrm{s}$ & $6.9 \%$ & $\sim 100 \mu \mathrm{s}$ & {$[1]$} \\
Chronaxie & $238 \mathrm{\mu s}$ & $9.8 \%$ & $264 \mathrm{\mu s}$ & {$[2]$} \\
Cond. velocity & $14 \mathrm{~m} / \mathrm{s}$ & & $12-14 \mathrm{~m} / \mathrm{s}$ & \\
Abs. ref. per. & $\mathbf{7 5 0 \mu \mathrm { s }}$ & & $300-500 \mu \mathrm{\mu s}$ & {$[25],[26]$} \\
Rel. ref. per. & $4.6 \mathrm{~ms}$ & $8.0 \%$ & $5 \mathrm{~ms}$ & {$[3],[4]$} \\
\hline
\end{tabular}

the correctly-predicted values, latency, jitter, and relative spread are compared to the values observed in single auditory nerve fibers of cats [1]. Relative spread recorded by Miller et al. in [27] as $6.28 \pm 4.4 \%(\mathrm{n}=140)$, is reported as $6.3 \%$ (as in [1]), which is $7.9 \%$ higher than our model's $5.8 \%$. For chronaxie, we used the mean $(264 \pm 84 \mu \mathrm{s})$ of 28 measurements from a feline experiment as the target value for our model [2].

Due to a great variability in reported measurements of absolute refractory periods, we present a range of 300 to $500 \mu \mathrm{s}$ as the reference values ([2], [25] and [26], respectively). Although our result of $750 \mu \mathrm{s}$ is close to $700 \mu \mathrm{s}$ used in [57] and the ARP measured in human ECAP data ( "> $500 \mu s$," [58]), it falls outside of our reference range of feline ARPs. One should note that the latest single-fiber experiments conducted by Miller et al. measure feline ARP as $332 \pm 98 \mu \mathrm{s}$ ( $\mathrm{n}=20$ fibers), which suggests that the value of the absolute refractory period is at the lower end of our reference range, closer to $300 \mu \mathrm{s}$, rather than $500 \mu \mathrm{s}$ [25]. Our model's prediction of the relative refractory period of $4.6 \mathrm{~ms}$, on the other hand, is fairly close to the $5 \mathrm{~ms}$ measured in felines [3], [4], as well as in humans, [58].

\section{B. Population Response}

To measure how well a diameter-distributed model predicts response characteristics of a population of fibers, we compared threshold distribution of 230 model fibers to the normalised thresholds observed by Miller et al. [1]. Diameters of the model fibers were randomly selected from a Gaussian distribution $(2.0 \pm 0.5 \mu \mathrm{m})$, parameters for which were based on the estimates of mean and standard deviation for auditory nerves in cats [59].

As can be seen in Fig. 3, thresholds of our neural population model closely approximate the range $(23.7 \mathrm{~dB}$ vs. $23.5 \mathrm{~dB}$ ) and the overall shape of the log-normal distribution measured in [1]. Such a close correspondence between physiological and simulated results suggests that a diameter-distributed model may be an adequate firstorder model of excitation behavior for a population of neurons activated by a monopolar electrode.

\section{Comparing Encoding Strategies}

To demonstrate how a population of model fibers responds to different speech encoding strategies, we stimulated 230 fibers (the same population as in the previous 


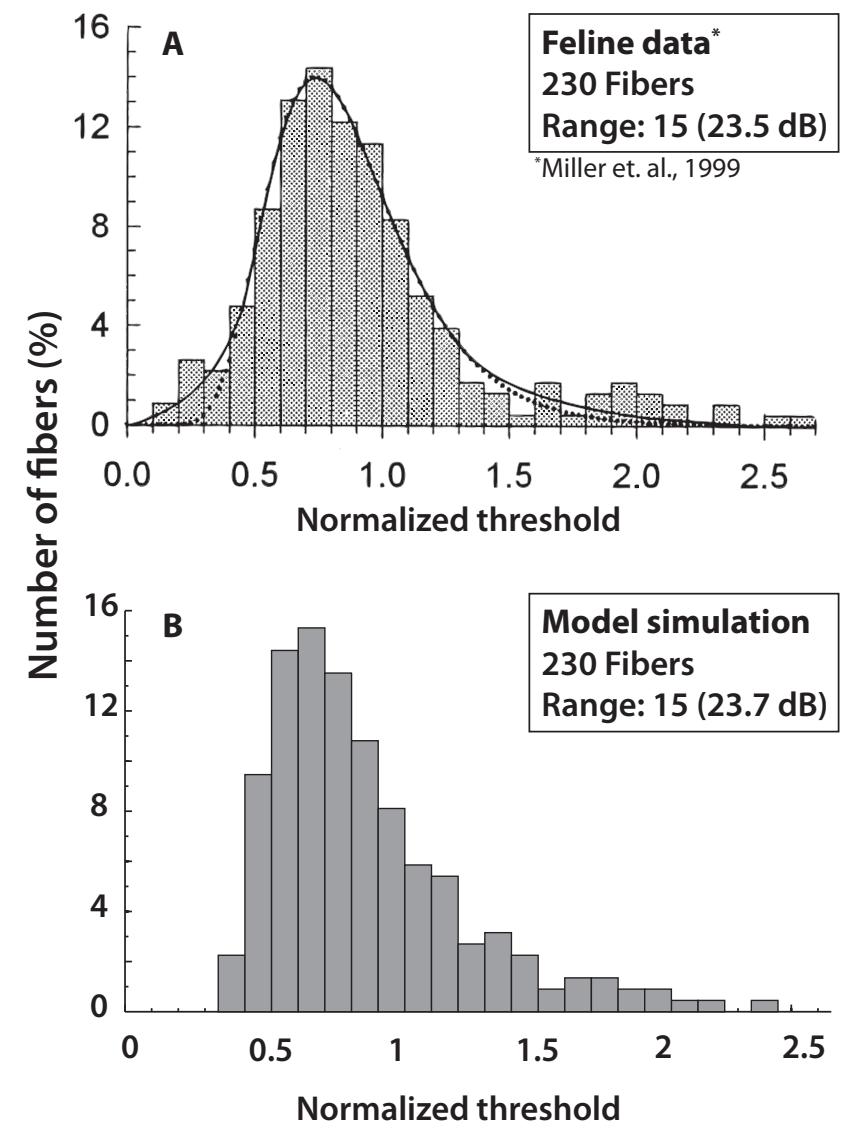

Fig. 3. Comparison of A) Experimentally-obtained normalised thresholds in [1] to $\mathbf{B})$ Matched model response.

section) with CA- and CIS- encoded signals ([30] and [29], respectively). As input, we used two $50 \mathrm{~Hz}$ Schroederphase signals (see "Stimulation" and Fig. 4, "Input sound" subpanels $\mathrm{A}^{-}$and $\mathrm{A}^{+}$). Because the envelopes of the two signals are the same, the primary difference between a positive and a negative Schroeder phase complex lies in its temporal fine structure (TFS; [55], [56]).

Raster plots in Fig. 4 (subpanels B and C) show the times at which differently-sized fibers produced a spike. The excitation patterns shown in subpanels $\mathrm{B}^{+}$and $\mathrm{B}^{-}$ (CIS-encoded positive and negative Schroeder phase, respectively) are fairly similar to each other. One can see that the CIS stimulus captured only the envelope of the signal; therefore, once stochasticity of the simulation is taken into account, the raster plots in $\mathrm{B}^{+}$and $\mathrm{B}^{-}$are largely the same. On the other hand, responses to $\mathrm{CA}^{-}$ encoded sounds shown in subpanels $\mathrm{C}^{+}$and $\mathrm{C}^{-}$are quite different from each other, with neural responses in $\mathrm{C}^{+}$ resembling a shifted, time-reversed spike pattern seen in $\mathrm{C}^{-}$. We provide some of the reasons as to why these two encoding strategies engender such markedly different neural responses in the Discussion section below.

\section{Discussion}

This study described a stochastic model of the auditory nerve which faithfully reproduces the excitation charac- teristics of single fibers, as well as that of a population. Parameters for our model were estimated by considering measurements that have been reported in the literature as a starting point, and then refining our estimates within a reasonable range of variation. We recognise that some of the biophysical parameters in the published literature are better studied than others; therefore, our approach aimed to deviate from well-established quantities as little as possible. Additionally, to reflect the measurement error of in vivo data, throughout model fitting, we preferred to alter several parameters in moderation, as opposed to altering a few by a lot.

Coupled with information metrics and signal detection theory, our model can potentially be used to predict the behavioral outcomes of cochlear stimulation, thereby shortening time-consuming behavioral experiments by pre-screening promising stimulation strategies during their development stages. Our immediate goal is to measure how well cochlear sound encoding strategies convey sensory information to the auditory nerve. Specifically, we plan to use results of behavioral studies (e.g., [54]) to inform us of the functional capabilities of the auditory system and information-theoretic approach to quantify the maximal amount of information contained in the neural discharge patterns (cf. [60], [61]). In effect, the informational approach will establish the smallest degree of difference necessary for stimuli discrimination by an ideal observer, while the behavioral data will inform us how well these differences in neural response patterns are perceived by the study subjects.

As shown in behavioral studies of human listeners, internal timing structure of the auditory waveform often corresponds to the perceived qualities of pitch, timbre, and rhythm. Using the fact that different types of auditory stimuli can evoke equivalent perception of pitch, Cariani demonstrated that the intervals between spike arrival times on a feline auditory nerve correspond to the autocorrelation function of the stimulus waveform [62]. Except in cases of octave shifts, the temporal, populationinterval representation of pitch accounted for perception of a number of complex pitch phenomena, as well as perception of timbre characteristic of different vowel stimuli [62], [63]. This suggests that it should be possible to evaluate the relative abilities of simulated CI encoding strategies to capture sensory information such as timbre and pitch by observing their respective excitation patterns.

\section{A. Comparing Encoding Strategies}

As a proof of concept, we used our population model to simulate and visualise neural responses of 230 auditory nerve fibers to two sound encoding strategies, CIS and CA (see Fig. 4). While the differences between CIS and CA encoding strategies are well-known and CIS' inability to encode temporal fine structure is expected from first principles (e.g., compare stimuli in subpanels $\mathrm{B}^{+}$and $\mathrm{B}^{-}$), this visualisation is the first practical demonstration of the biophysics of TFS encoding by a cochlear implant signal processing strategy. 

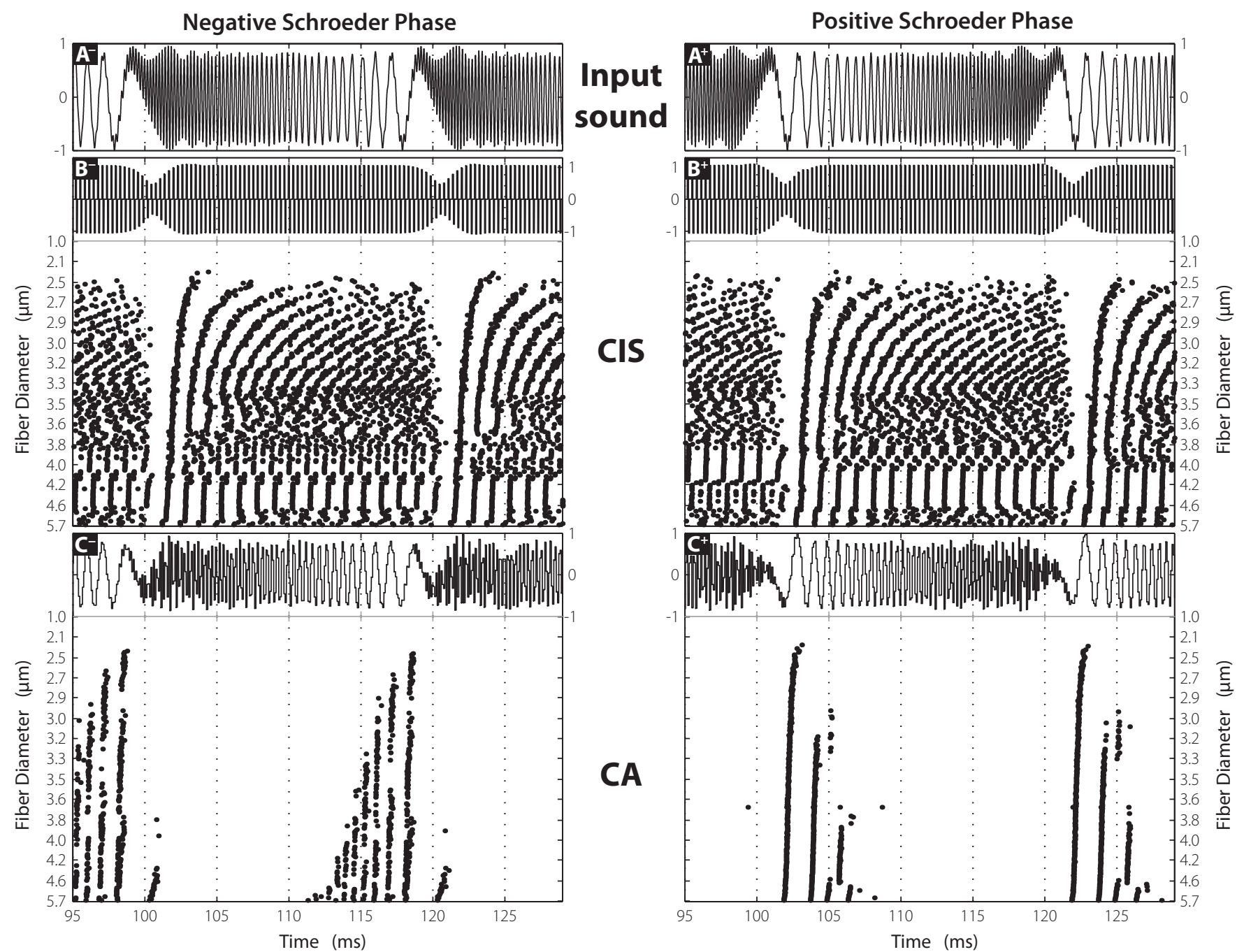

Fig. 4. Responses of a neural population model to $50 \mathrm{~Hz}$ positive and negative Schroeder phase input signals ( + and - , respectively). A) Amplitudes of input signals; B) Top panel: Input sound encoded with CIS coding strategy; bottom panel: spike output of a neural population model in response to input sound encoded with CIS. C) Same as "B", only coding was done with CA strategy.

Of particular interest, note how the discharge patterns differ between $\mathrm{CA}$-encoded positive and negative Schroeder phase stimuli: in response to negative Schroeder phase, spikes appear first in large-diameter fibers, later on spreading to smaller-diameter fibers with correspondingly higher thresholds of excitation (e.g., $t=112$ to $119 \mathrm{~ms}$ in $\mathrm{C}^{-}$, note how it forms an "increasing triangle" pattern). Responses to positive SP exhibit the reverse trend: first, both large- and small- diameter fibers fire at the same time, with smaller-fiber diameters remaining quiescent later on (e.g., the "decreasing triangle" pattern during $t=102$ to $110 \mathrm{~ms}$ in $\mathrm{C}^{+}$). Also note that excitations in response to positive Schroeder phase signals occur roughly at the same time, with little temporal variability in excited fibers (see $\mathrm{C}^{+}$at $t=102$ and $122 \mathrm{~ms}$, for example). On the other hand, responses to $\mathrm{CA}$-encoded negative Schroeder phase signals display more non-uniformity, such as at $t=98$ and $118 \mathrm{~ms}$ in $\mathrm{C}^{-}$.

Even though the stimulus waveforms for the positive and negative Schroeder phase stimuli look dissimilar once encoded with the CA strategy, by itself, that does not imply that the listener will perceive the two sounds as being different from each other. To be perceptually relevant, the difference between the two input waveforms must be preserved at the neural level, with each type of stimulus evoking a distinct spike train. Because the model output in Fig. 4 demonstrates that the divergence between CAencoded positive and negative Schroeder phase sounds remains at the level of AN fibers, it follows that this contrast is potentially available to the auditory nervous system. We believe it is the disparities in the neural excitation patterns that are responsible for the CI users' ability to discriminate positive from negative $50 \mathrm{~Hz}$ Schroeder phase signals in CA-, but not CIS- encoded signals [54].

\section{B. Limitations of the Model}

There are several limitations to our model. First and foremost, we do not explicitly account for the geometric distances and the spatial distribution of the intervening tissues in our model. To model the space between the 
stimulating electrode and the fiber, we assume it to be an isotropic medium a given electrical distance away, which accounts for the resistivity and diffusivity of the intervening media. Omitting tissue inhomogeneities and interactions of the electric fields simplifies our model, although both Frijns et al. and Mino et al., have demonstrated a spatio-temporal variation of neural excitation in response to changes in geometry of the tissues [18], [35]. Given the above, our model presents an idealised case of monopolar cochlear implant stimulation, as it contains an explicit assumption of electrode-to-electrode independence.

Although our model contains slow potassium channels to account for spike-frequency adaptation and subthreshold accommodation [48], time constant of the delayed rectifier is not long enough to encompass short-term neural adaptation that occurs within first 100 to $300 \mathrm{~ms}$ of continuous stimulation [64]. To accurately model neural excitation in response to electrical stimulation with a typical speech encoding strategy, we need to incorporate adaptation in our model. Fortunately, adaptation to electric stimuli is the subject of recent research efforts, due in part to its relevance to speech processing in cochlear implants [65]. In the near future, we expect to add shortterm adaptation to trains of electric pulses (250 to 5000 pulses/s), such as the one described in Woo et al.'s model in [65].

\section{ACKNOWLEDGMENT}

The authors would like to thank Jeff Longnion for his early contributions to the project, as well as Jong $\mathrm{H}$. Won and Ward R. Drennan for fruitful discussions. This research was supported by NIH grants R01-DC007525 and P30-DC04661.

\section{REFERENCES}

[1] C. Miller, P. Abbas, and J. T. Rubinstein, "An empirically based model of the electrically evoked compound action potential," Hear Res, vol. 135, pp. 1-18, 1999.

[2] P. Stypulkowski and C. van den Honert, "Physiological properties of the electrically stimulated auditory nerve. I. Compound action potential recordings." Hear Res, vol. 14, no. 3, pp. 20523, 1984 .

[3] R. Hartmann, G. Topp, and R. Klinke, "Discharge patterns of cat primary auditory fibers with electrical stimulation of the cochlea." Hear Res, vol. 13, no. 1, pp. 47-62, 1984.

[4] S. B. C. Dynes, "Discharge characteristics of auditory nerve fibers for pulsatile electrical stimuli," Ph.D. dissertation, Massachusetts Institute of Technology, Cambridge, MA, 1996.

[5] F.-G. Zeng, S. Rebscher, W. Harrison, X. Sun, and H. Feng, "Cochlear implants: System design, integration, and evaluation," IEEE Rev in Biomed Eng, vol. 1, pp. 115-142, 2008.

[6] B. Moore, "The role of temporal fine structure processing in pitch perception, masking, and speech perception for normalhearing and hearing-impaired people," J Assoc Res Otolaryngol, vol. 9, no. 4, pp. 399-406, Dec. 2008.

[7] R. Laszig, A. Asschendorf, M. Stecker, J. Muller-Deile, S. Maune, N. Dillier, B. Weber, M. Hey, K. Begall, T. Lenarz, R. Battmer, M. Bohm, T. Steffens, J. Strutz, T. Linder, R. Probst, J. Allum, M. Westhofen, and W. Doering, "Benefits of bilateral electrical stimulation with the nucleus cochlear implant in adults: 6-month postoperative results," Otol Neurotol., vol. 25 , no. 6 , pp. 958-968, 2004
[8] B. Wilson, R. Schatzer, E. Lopez-Poveda, X. Sun, D. Lawson, and R. Wolford, "Two new directions in speech processor design for cochlear implants," Ear and Hearing, vol. 26, no. 4, pp. 73S$81 \mathrm{~S}, 2005$.

[9] L. Xu, Y. Tsai, and B. E. Pfingst, "Features of stimulation affecting tonal-speech perception: Implications for cochlear prostheses," J Acoust Soc Am, vol. 112, no. 1, pp. 247-258, 2002.

[10] Z. M. Smith, B. Delgutte, and A. J. Oxenham, "Chimaeric sounds reveal dichotomies in auditory perception," Nature, vol. 416, no. 6876, pp. 87-90, 2002.

[11] Y. Kong, R. Cruz, J. Jones, and F. Zeng, "Music perception with temporal cues in acoustic and electric hearing," Ear and Hearing, vol. 25, no. 2, pp. 173-185, 2004.

[12] F. Rattay, P. Lutter, and H. Felix, "A model of the electrically excited human cochlear neuron I. contribution of neural substructures to the generation and propagation of spikes," Hear Res, vol. 153, pp. 43-63, 2001.

[13] J. J. Briaire and J. H. Frijns, "The consequences of neural degeneration regarding optimal cochlear implant position in scala tympani: a model approach," Hear Res, vol. 214, no. 1-2, pp. $17-27,2006$.

[14] H. Mino, J. T. Rubinstein, and J. A. White, "Comparison of algorithms for the simulation of action potentials with stochastic sodium channels," Ann Biomed Eng, vol. 30, pp. 578-87, 2002.

[15] O. Macherey, R. Carlyon, A. van Wieringen, and J. Wouters, "A dual-process integrator-resonator model of the electrically stimulated human auditory nerve," J Assoc Res Otolaryngol, vol. 8, no. 1, pp. 84-104, Mar. 2007.

[16] L. A. Cartee, "Evaluation of a model of the cochlear neural membrane. II: comparison of model and physiological measures of membrane properties measured in response to intrameatal electrical stimulation," Hear Res, vol. 146, pp. 153-66, 2000.

[17] — , "Spiral ganglion cell site of excitation II: Numerical model analysis," Hear Res, vol. 215, no. 1-2, pp. 22-30, May 2006.

[18] J. Frijns, S. de Snoo, and R. Schoonhoven, "Potential distributions and neural excitation patterns in a rotationally symmetric model of the electrically stimulated cochlea," Hear Res, vol. 87, pp. 170-186, 1995.

[19] I. C. Bruce, M. White, L. S. Irlicht, S. O'Leary, S. Dynes, E. Javel, and G. Clark, "A stochastic model of the electrically stimulated auditory nerve: Single-pulse response," IEEE Trans Biomed Eng, vol. 46, no. 6, pp. 617-29, 1999.

[20] E. Javel and N. Viemeister, "Stochastic properties of cat auditory nerve responses to electric and acoustic stimuli and application to intensity discrimination," J Acoust Soc Am, vol. 107, no. 2, pp. 908-21, 2000.

[21] Y. Xu and L. Collins, "Predicting dynamic range and intensity discrimination for electrical pulse-train stimuli using a stochastic auditory nerve model: The effects of stimulus noise," IEEE Trans Biomed Eng, vol. 52, no. 6, pp. 1040-9, 2005.

[22] J. A. White, J. T. Rubinstein, and A. R. Kay, "Channel noise in neurons," Trends Neurosci, vol. 23, pp. 131-7, 2000.

[23] J. T. Rubinstein, "Threshold fluctuations in an n-sodium channel model of the node of Ranvier," Biophys J, vol. 68, no. 3, pp. 779-785, 1995.

[24] A. J. Matsuoka, J. T. Rubinstein, P. J. Abbas, and C. A. Miller, "The effects of interpulse interval on stochastic properties of electrical stimulation: Models and measurements," IEEE Trans Biomed Eng, vol. 48, no. 4, pp. 416-24, 2001.

[25] C. A. Miller, P. J. Abbas, and B. K. Robinson, "Response properties of the refractory auditory nerve fiber," $J$ Assoc Res Otolaryngol, vol. 2, pp. 216-232, 2001.

[26] C. Brown and P. Abbas, "Electrically evoked whole-nerve action potentials: parametric data from the cat." J Acoust Soc Am, vol. 88 , no. 5 , pp. 2205-10, 1990.

[27] C. A. Miller, P. J. Abbas, B. K. Robinson, J. T. Rubinstein, and A. Matsuoka, "Electrically evoked single-fiber action potentials from cat: responses to monopolar, monophasic stimulation." Hear Res, vol. 130, pp. 197-218, 1999.

[28] L. A. Cartee, C. A. Miller, and C. van den Honert, "Spiral ganglion cell site of excitation I: Comparison of scala tympani and intrameatal electrode responses," Hear Res, vol. 215, no. 1-2, pp. 10-21, May 2006.

[29] B. S. Wilson, C. C. Finley, D. T. Lawson, R. D. Wolford, D. K. Eddington, and W. M. Rabinowitz, "Better speech recognition with cochlear implants," Nature, vol. 352, no. 6332, pp. 236-238, Jul. 1991. 
[30] D. K. Eddington, W. H. Dobelle, D. E. Brackmann, M. G. Mladejovsky, and J. L. Parkin, "Auditory prostheses research with multiple channel intracochlear stimulation in man." Ann Otol Rhinol Laryngol, vol. 87, no. 6 Pt 2, pp. 1-39, 1978.

[31] M. Liberman and M. Oliver, "Morphometry of intracellularly labeled neurons of the auditory nerve: correlation with functional properties," J Comp Neurol, vol. 223, no. 2, pp. 163-76, 1984.

[32] A. R. Arnesen and K. K. Osen, "The cochlear nerve in the cat: Topography, cochleotopy, and fiber spectrum," J Comp Neurol, vol. 178 , no. 4 , pp. $661-678,1978$.

[33] P. Basser, "Scaling laws for myelinated axons derived from an electrontonic core-conductor model," J Integr Neurosci, vol. 3, no. 2 , pp. $227-244,2004$.

[34] C. Berthold, Physiology and Pathobiology of Axons. Raven Press, New York, 1978, ch. Morphology of normal peripheral axons, pp. 3-64.

[35] H. Mino, J. T. Rubinstein, C. A. Miller, and P. J. Abbas, "Effects of electrode-to-fiber distance on temporal neural response with electrical stimulation," IEEE Trans Biomed Eng, vol. 51, no. 1 , pp. 13-20, 2004

[36] J. H. Caldwell, K. L. Schaller, R. S. Lasher, E. Peles, and S. R. Levinson, "Sodium channel Nav1.6 is localized at nodes of Ranvier, dendrites, and synapses," Proc. Natl. Acad. Sci. U. S. A., vol. 97 , no. 10 , pp. 5616-5620, 2000.

[37] B. Hille, Ion channels of excitable membranes. Sunderland, Mass.: Sinauer, 2001.

[38] F. J. Sigworth, "The variance of sodium current fluctuations at the node of Ranvier," J Physiol, vol. 307, pp. 97-129, 1980.

[39] F. J. Sigworth and E. Neher, "Single Na+ channel currents observed in cultured rat muscle cells," Nature, vol. 287, no. 5781, pp. 447-449, Oct. 1980.

[40] B. Neumcke and R. Stampfli, "Sodium currents and sodiumcurrent fluctuations in rat myelinated nerve fibers," $J$ Physiol, vol. 329 , no. 1 , pp. 163-84, 1982

[41] B. V. Safronov, K. Kampe, and W. Vogel, "Single voltagedependent potassium channels in rat peripheral nerve membrane." J Physiol, vol. 460, no. 1, pp. 675-691, 1993.

[42] J. R. Schwarz, G. Glassmeier, E. C. Cooper, T.-C. Kao, H. Nodera, D. Tabuena, R. Kaji, and H. Bostock, "KCNQ channels mediate IKs, a slow $\mathrm{K}+$ current regulating excitability in the rat node of Ranvier," J Physiol, vol. 573, no. 1, pp. 17-34, 2006.

[43] G. Reid, A. Scholz, H. Bostock, and W. Vogel, "Human axons contain at least five types of voltage-dependent potassium channel," J Physiol, vol. 518, no. 3, pp. 681-696, 1999.

[44] S. G. Waxman, J. D. Kocsis, and P. K. Stys, The axon : structure, function, and pathophysiology. New York: Oxford University Press, 1995.

[45] A. Scholz, G. Reid, W. Vogel, and H. Bostock, "Ion channels in human axons," J Neurophysiol, vol. 70, no. 3, pp. 1274-9, 1993.

[46] C. McIntyre, A. Richardson, and W. Grill, "Modeling the excitability of mammalian nerve fibers: Influence of afterpotentials in the recovery," J Neurophysiol, vol. 87, no. 995-1006, 2002.

[47] C. Koch and S. Idan, Methods in neuronal modeling : from ions to networks. Cambridge, Mass.: MIT Press, 1998.

[48] J. Schwarz, G. Reid, and H. Bostock, "Action potentials and membrane currents in the human node of Ranvier," Eur J Physiol, vol. 430, pp. 283-292, 1995.

[49] T. Brismar, "Electrical properties of isolated demyelinated rat nerve fibres." Acta Physiol Scand, vol. 113, pp. 161-6, 1981.

[50] I. Tasaki, "New measurements of the capacity and the resistance of the myelin sheath and the nodal membrane of the isolated frog nerve fiber," Am J Physiol, vol. 181, no. 3, pp. 639-650, 1955.

[51] J. Frijns, J. Mooij, and J. ten Kate, "A quantitative approach to modeling mammalian myelinated nerve fibers for electrical prosthesis design," IEEE Trans Biomed Eng, vol. 41, no. 6, pp. 556-66, 1994.

[52] J. T. Rubinstein, "Axon termination conditions for electrical stimulation," IEEE Trans Biomed Eng, vol. 40, no. 7, pp. 65463, 1993.

[53] C. A. Miller, B. Robinson, J. T. Rubinstein, P. Abbas, and C. Runge-Samuelson, "Auditory nerve responses to monophasic and biphasic stimuli," Hear Res, vol. 151, pp. 79-94, 2001.

[54] J. H. Won, W. R. Drennan, E. Jameyson, and J. T. Rubinstein, "Single-channel Schroeder-phase test as a measure of withinchannel temporal fine-structure sensitivity," in ARO 2009 MidWinter Meeting, Feb., 2009, poster presentation.
[55] R. J. Dooling, M. L. Dent, M. R. Leek, and O. Gleich, "Masking by harmonic complexes in birds: behavioral thresholds and cochlear responses," Hear Res, vol. 152, pp. 159-72, 2001.

[56] W. Drennan, J. Longnion, C. Ruffin, and J. Rubinstein, "Discrimination of Schroeder-phase harmonic complexes by normalhearing and cochlear-implant listeners," J Assoc Res Otolaryngol., vol. 9, no. 1, pp. 138-149, 2008.

[57] L. A. Cartee, C. van den Honert, C. C. Finley, and R. L. Miller, "Evaluation of a model of the cochlear neural membrane. I: Physiological measurement of membrane characteristics in response to intrameatal electrical stimulation," Hear Res, vol. 146, no. 1-2, pp. 143-152, Aug. 2000.

[58] C. J. Brown, P. J. Abbas, and B. Gantz, "Electrically evoked whole-nerve action potentials: Data from human cochlear implant users," J Acoust Soc Am, vol. 88, no. 3, pp. 1385-91, 1990.

[59] P. Abbas and C. A. Miller, "Biophysics and physiology," in Cochlear Implants: Auditory Prostheses and Electric Hearing, ser. Springer Handbook of Auditory Research, F. Zeng, A. Popper, and R. Fay, Eds. New York: Springer Verlag, 2004, vol. 20, pp. 149-212.

[60] R. D. R. V. Steveninck and W. Bialek, "Reliability and statistical efficiency of a blowfly movement-sensitive neuron," Phil Trans $R$ Soc B, vol. 348, no. 1325, pp. 321-40, 1995.

[61] Y. Xu and L. Collins, "Predictions of psychophysical measurements for sinusoidal amplitude modulated (SAM) pulse-train stimuli from a stochastic model," IEEE Trans Biomed Eng, vol. 54, no. 8, pp. 1389-98, 2007.

[62] P. Cariani, "Temporal coding of periodicity pitch in the auditory system: An overview," Neural Plasticity, vol. 6, no. 4, pp. 147172,1999

[63] - "Temporal codes, timing nets, and music perception," $J$ New Music Res, vol. 30, no. 2, pp. 107-135, 2001.

[64] R. L. Smith, "Short-term adaptation in single auditory nerve fibers: some poststimulatory effects," J Neurophysiol, vol. 40, no. 5 , pp. $1098-111,1977$.

[65] J. Woo, C. A. Miller, and P. J. Abbas, "Simulation of the electrically stimulated cochlear neuron: modeling adaptation to trains of electric pulses," IEEE Trans Biomed Eng, 2009 (in press).

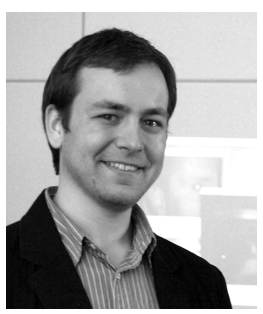

Nikita S. Imennov received his B.Sc. degrees in Biomedical Engineering (with Distinction) and Computer Science (Cum Laude) from the University of Rochester (Rochester, NY) in 2004. He is currently pursuing a Ph.D. degree in Bioengineering at the University of Washington (Seattle, WA). His research interests include computational neuroscience, stochastic modeling, signal processing, and large-scale parallel programming.

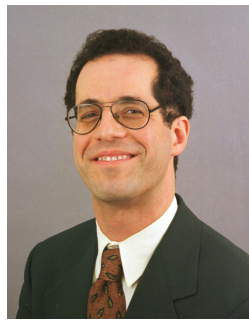

Jay T. Rubinstein received $\mathrm{ScB} / \mathrm{ScM}$ degrees in Engineering at Brown University in 1981/83. He received an MD and PhD in Bioengineering at the University of Washington in $1987 / 88$. He completed postdoctoral research training and residency in Otolaryngology in 1994 at the Massachusetts Eye and Ear Infirmary. He completed a Neurotology fellowship at the University of Iowa in 1995 staying as Assistant then Associate Professor of Otolaryngology and Bioengineering. In 2003/04 he was the Boerhaave Professor at Leiden University, the Netherlands. He is currently Virginia Merrill Bloedel Professor of Otolaryngology and Bioengineering and Director, Bloedel Hearing Research Center, University of Washington. He is President-elect of the American Auditory Society, on Council of the Association for Research in Otolaryngology, and a permanent member of the auditory science study section at the National Institutes of Health. 